\title{
Identification of molecular pathways and prognostic biomarkers with survival analysis associated with UV-mediated skin cancer by bioinformatics approaches
}

Md Habibur Rahman ( $\square$ habib@iu.ac.bd)

Islamic University

Arju Hossain

Mawlana Bhashani Science and Technology University

Asif Ahsan

Mawlana Bhashani Science and Technology University

Imran Hasan

Islamic University

Md Sohel

Mawlana Bhashani Science and Technology University

Arif Khan

University of Development Alternative

Md Sipon Miah

Islamic University

Research Article

Keywords: Skin Cancer, Bioinformatics, Biomarker, Pathways, Hub Proteins

Posted Date: February 25th, 2022

DOI: https://doi.org/10.21203/rs.3.rs-1373879/v1

License: (c) (1) This work is licensed under a Creative Commons Attribution 4.0 International License.

Read Full License 


\title{
Identification of molecular pathways and prognostic biomarkers with survival analysis associated with UV-mediated skin cancer by bioinformatics approaches
}

\author{
Md. Arju Hossain ${ }^{\mathrm{a}}$, Asif Ahsan ${ }^{\mathrm{a}}$, Md. Imran Hasan ${ }^{\mathrm{b}}$, Md Sohel ${ }^{\mathrm{c}}$, Md. Arif Khan ${ }^{\mathrm{d}}$, Md Sipon Miah ${ }^{\mathrm{e}}$, \\ Md Habibur Rahman ${ }^{\mathrm{b}}$ \\ ${ }^{a}$ Department of Biotechnology and Genetic Engineering; Mawlana Bhashani Science and Technology University Santosh \\ Tangail-1902. \\ ${ }^{b}$ Department of Computer Science and Engineering; Islamic University kushtia-7003 \\ ${ }^{c}$ Department of Biochemistry and Molecular Biology. Mawlana Bhashani Science and Technology University Santosh; \\ Tangail-1902. \\ ${ }^{d}$ Department of Biotechnology $\mathscr{G}$ Genetic Engineering. University of Development Alternative Dhaka-1209 Bangladesh. \\ ${ }^{e}$ Department of Information and communication Technology. Islamic University;kushtia-7003.
}

\begin{abstract}
Skin cancer (SC) referred to as cutaneous carcinoma is a serious public health concern on a global scale particularly for those with fair skin. Ultraviolet (UV) radiation causes skin cancer, but the exact mechanism by which occurs and the most effective methods of intervention to prevent it are yet unknown. Using bioinformatic approaches several biomarkers have been identified to determine the severity of skin cancer. This study will use bioinformatics and pharmacology approaches to discover potential biomarkers of SC for early diagnosis, prevention of disease, and therapeutic target identification.

This study compared gene expression and protein levels in UV-mediated cultured keratinocytes and adjacent normal skin tissue using RNA sequencing data from the NCBI-GEO database. Then we employed GO and signalling pathway database, selection of hub genes from protein-protein interaction (PPI) network, survival and expression profile, and gene regulatory network analysis to screen potential clinical biomarkers.

In the study, we identified 32 shared differentially expressed genes (DEGs) including 19 upregulated genes and 13 downregulated genes by analyzing three different subsets of the GSE85443 dataset. Skin cancer development is related to control of several DEGs through cyclin-dependent protein serine/threonine kinase activity, cell cycle regulation and activation of the NIMA kinase pathways. The cytohubba plugin in Cytoscape identified twelve hub genes from PPI; among these three DEGs namely, AURKA, CDK4, and PLK1 were shown to be significantly associated with survival $(\mathrm{p}<0.05)$ and highly expressed in SC tissues. Transcriptional, post-transcriptional, and protein-chemical also indicates the hub genes bound to several molecules. Further investigation and clinical experiments will be needed to evaluate the expression of these identified biomarkers regarding the prognosis of SC patients.
\end{abstract}

Keywords: Skin Cancer, Bioinformatics, Biomarker, Pathways, Hub Proteins

\section{Introduction}

The impacts of climate change on human health are ubiquitous and there is significant concern that the earth's atmosphere will continue to warm adversely. Since the middle of the twentieth century, the global incidence of skin cancer has increased at an alarming rate. Skin cancer also known as cutaneous carcinoma is a prominent global health issue especially the higher risk of the population with fair skin than darker skin 36. Globally, in 20192.4 million squamous cell carcinoma (SCC) and 4.0 million basal cell carcinoma patients were identified. On the other hand, invasive melanoma is the most malignant and most serious type of skin cancer accounts for 80 percent of all skin cancer-related fatalities [20]. There is an annual increase in melanoma incidence of 4 to 6 percent among fair-skinned people in Northern Europe, North America, Australia, and New Zealand [67].

\footnotetext{
${ }^{*}$ Corresponding author

Email address: habib@iu.ac.bd (Md Habibur Rahman)
} 
However, several variables contribute to the disease including genetic factors, UV light exposure, and environmental factors [19]. Among those, UVR (a potent carcinogen) exposure is the root cause of skin cancer [17, 46, 12, 15] which is responsible for the mutation of a number of cancer-suppressor genes like p53 [65], and p21 [45], gelatinases 61] and galectin-3 has the potential to be utilized as a marker to assess both sun exposure and the risk of cancer [47. In patients deficient in DNA repair enzymes such as xeroderma pigmentosa (XP), there is a significantly increased incidence of SCC [37]. EGFR is activated by UV light and upregulates several MAPKs [52, 30]. Phosphatidylinositol 3-kinase (PI3K)/AKT [24] signalling pathways whose deregulation is critical during tumor genesis to reduce cell death, increase cell proliferation, and enhance the process of epidermal hyperplasia. COX-2 is overexpressed in human skin actinic keratoses (premalignant UV induced skin lesions), SCCs, and BCCs, as well as in human epidermal cancer cell lines [1, 23.

Prognosis improves when lesions are found early including skin cancer that is melanoma and nonmelanoma, early detection and treatment are required to reduce the number of deaths due to skin cancer [12. However, given the difficulties of early detection and diagnosis, the overall survival rate of SC patients drops significantly. The above studies indicate that several biomarkers can explain the pathophysiology of SC and predict the consequences, but they still lack clinical studies. Therefore, more efficient biological markers should be investigated to fully understand SC's aetiology and guide treatment and prognosis.

The advancement of bioinformatics techniques, next-generation sequencing, proteomics, transcriptomics, and epigenetic research has enhanced our understanding of cancer growth and molecular processes and the design of appropriate drugs for the diseases. Recently, a promising technology called integrated system biology has been used to identify new molecular oncogenes and gene signatures utilizing Gene Expression Omnibus (GEO) gene expression profiles already in existence [32, 49, 40, 41]. Most existing bioinformatics studies focus on oncogene changes and neglect differences at the protein level, and molecular biology validation is seldom performed.

These protein-protein interactions are unique to the retrieval of putative hub genes, survival and expression level analysis of 12 hub genes, gene regulatory network and protein-drug-chemical interaction analysis of UV-mediated skin cancer. In this investigation, we have employed the bioinformatics and pharmacological approaches to explore the potential biomarker to understand better the molecular processes of skin cancer progression, early detection, and drug target identification through related signalling pathways. Our findings may serve as a clinical biomarker that helps us better understand the genesis of $\mathrm{SC}$ and predict its prognosis.

\section{Materials and Methods}

\subsection{Data Retrieval and Preparation of $S C$ Datasets}

The RNA-sequence gene expression data sample used in this study was reclaimed from the National Center for Biotechnology Information (NCBI) Gene Expression Omnibus database. We used gene expression data from human skin cancers with accession number GSE85443. Total RNA was isolated from UV-irradiated human keratinocytes cells in different UVR conditions and non-irradiated control keratinocytes cells using the Illumina HiSeq 2000 platform. For analysis purposes, we made three datasets as groups N0, N1 and N2 for the separated three control groups to identify UV-responsive dysregulated genes in human SCC. Details information of GEO SC "patients" data were tabulated in Table 1. Then Statistical operations, including moderate t-statistic, B-statistics, and moderated F-statistics for all the pair-wise comparisons were performed on the datasets to determine the DEGs. First, the BioJupies (https://maayanlab.cloud/biojupies/) generator online server was used for RNA-Seq raw data analysis 64. Additionally, the Benjamini-Hochberg false discovery rate approach is employed to balance the discovery of statistically significant genes and the limitation of false positives. In this study, genes with $\mathrm{p}$-value $<0.05$ and absolute $\log 2$ fold-change $>1$ were considered DEGs. We also considered $\log 2$ fold-change $\geq 1$ and $\log 2$ fold-change $\leq-1$ criteria to explore up and down-regulated genes, respectively. Following that, we analyzed three SC sub-datasets using the Venny v2.1 web tool to identify shared DEGs [20]. Flow diagram shows on (Figure 1]) system biology and bioinformatics approach on UV-mediated skin cancer .

\subsection{Functional Enrichment Analysis}

Pathway-based analysis is a recently established technique to understanding how complicated illnesses may be connected through their underlying biological processes [26]. On the other hand, gene ontology (GO) is a schema for describing gene activities and their connections to epigenetics [7]. We 


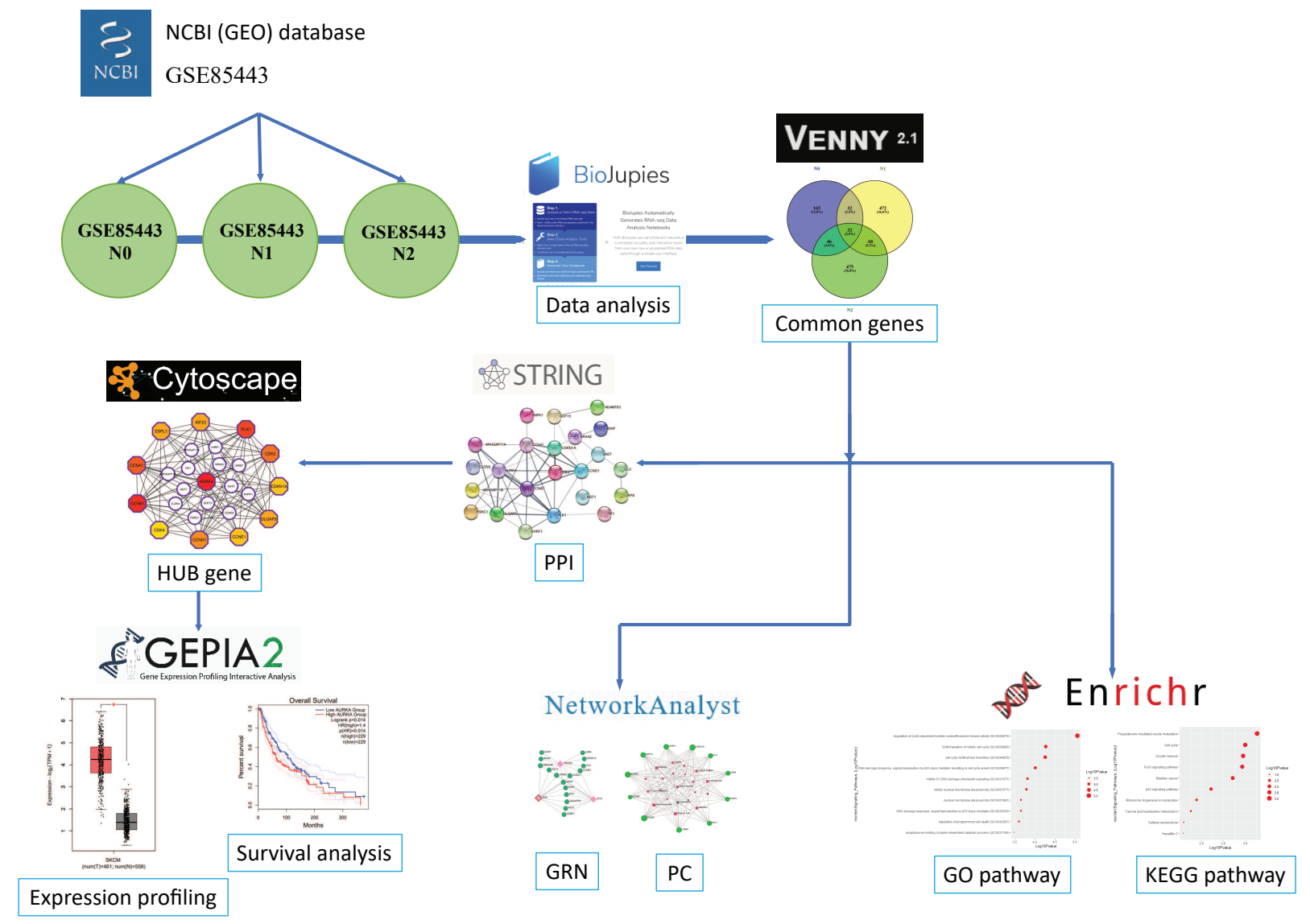

Figure 1: A schematic diagram of integrative bioinformatics analytical approach applied in this study. 
(A)

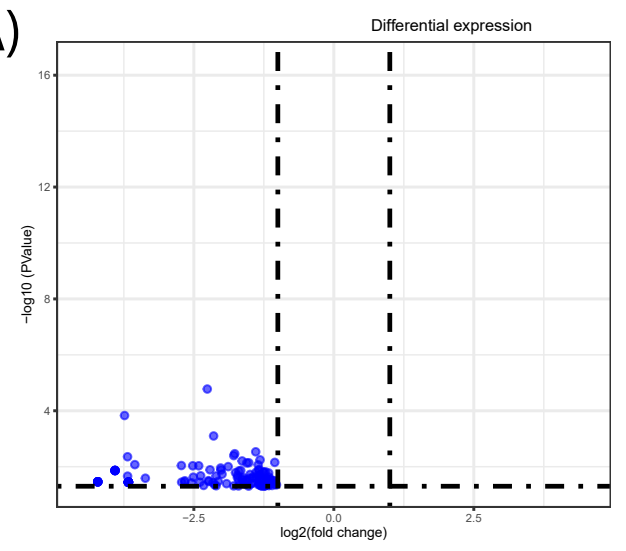

(B)

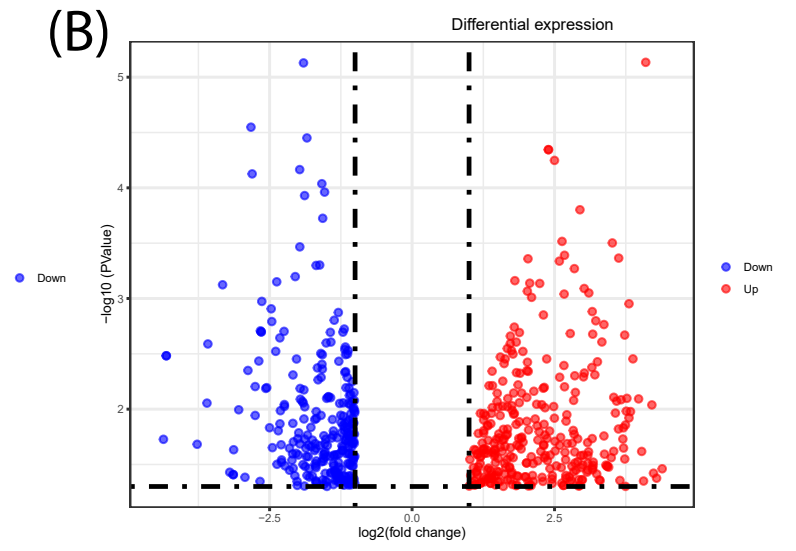

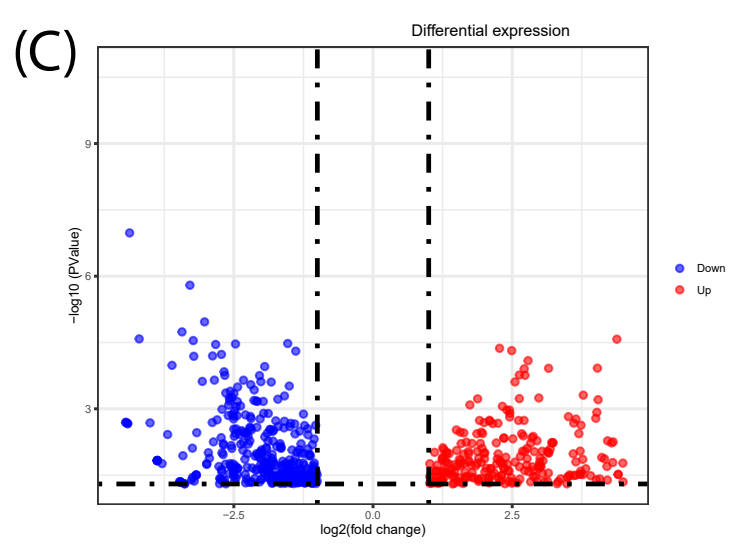

Figure 2: Volcano plot of the DEGs from datasets (A) GSE85443 N0, (B) GSE85443 N1, and (C) GSE85443 N2. X-axis: $\log \mathrm{FC}$, large-scale fold changes; $\mathrm{y}$-axis: $-\log 10$ of the p-value is showing the statistical significance. The red points present the up-regulated genes and the blue points represent the down-regulated genes. 


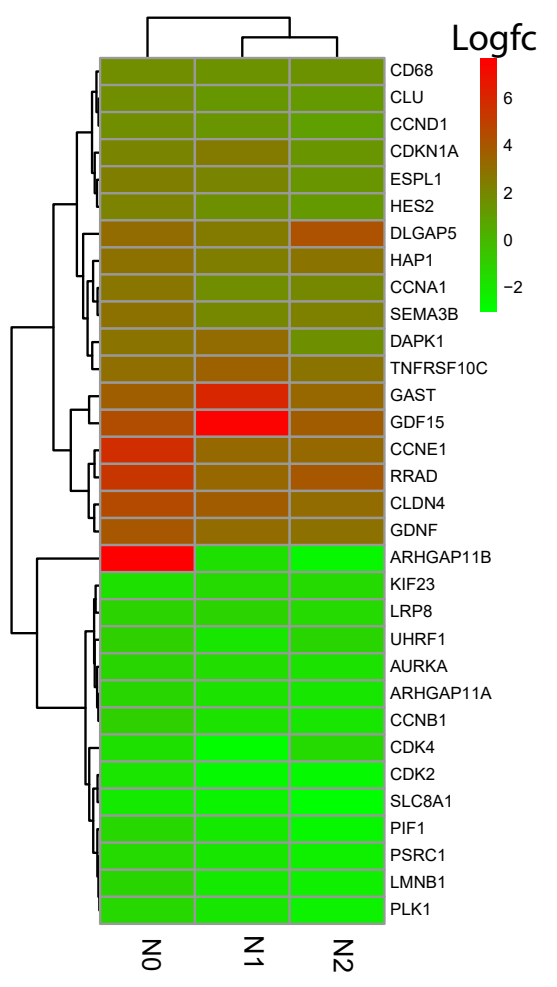

(A)

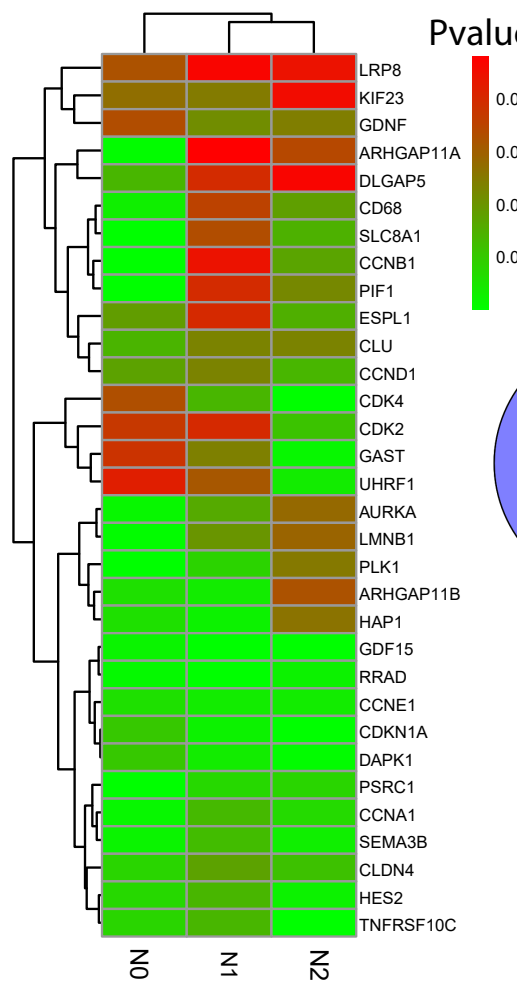

(B)

Figure 3: Heat map showing 32 DEGs between normal and skin cancer tissue in three groups of the GSE85443 datasets based on (A) $\log 2$ fold-change and (B) adjusted p-value. Identification of 32 common DEGs and co-expressed genes by comparing three subsets of datasets (GSE85443 N0, GSE85443 N1, and GSE85443 N2) through (C) Venn diagram software. Different color meant different datasets. These datasets have 19 up-regulated and 13 down-regulated genes. 
(A)

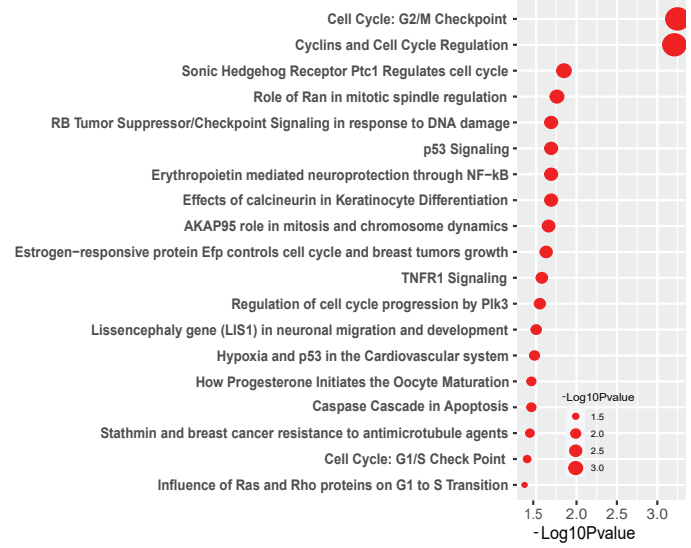

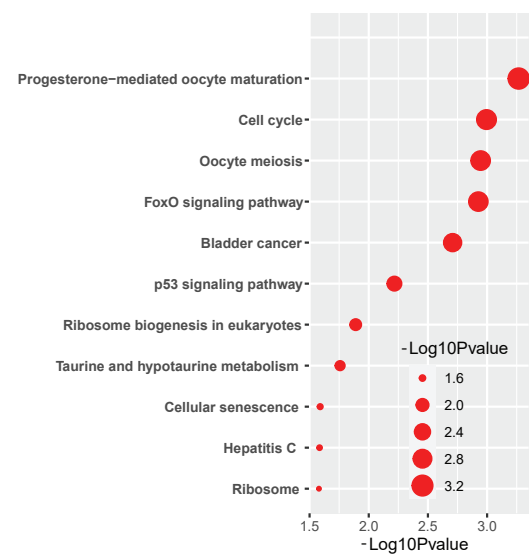

(C)

Figure 4: Functional enrichment analyses of the differentially expressed genes (DEGs) in skin cancer. (A) The results of GO analysis for pathway associated with biological process (BP), (B) The results of GO analysis for pathway associated with cellular component (CC), (C) The results of GO analysis for pathway associated with molecular function (MF) 
(A)

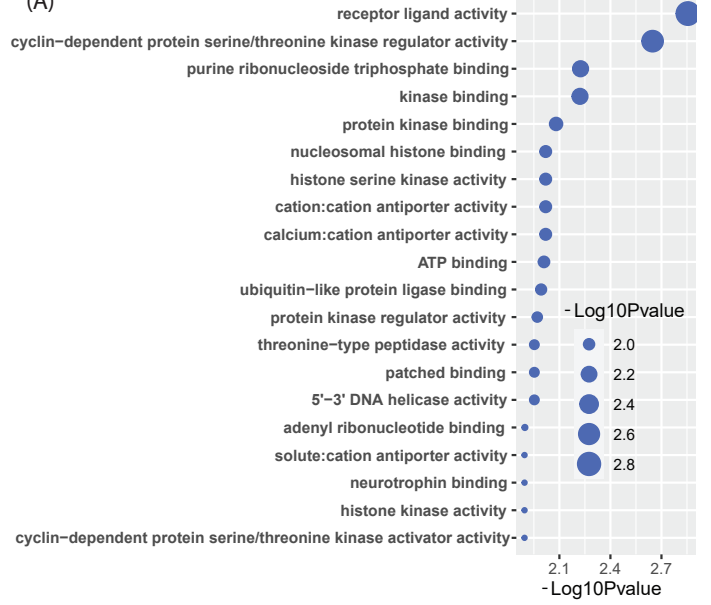

(B)

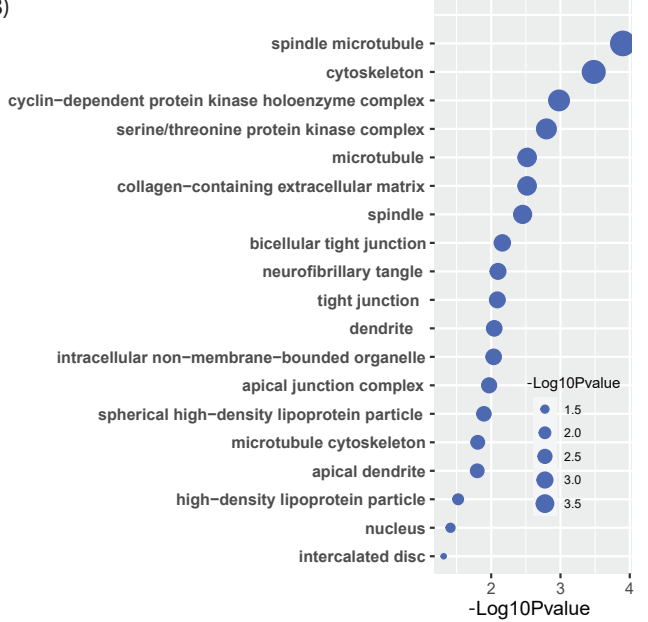

(C)

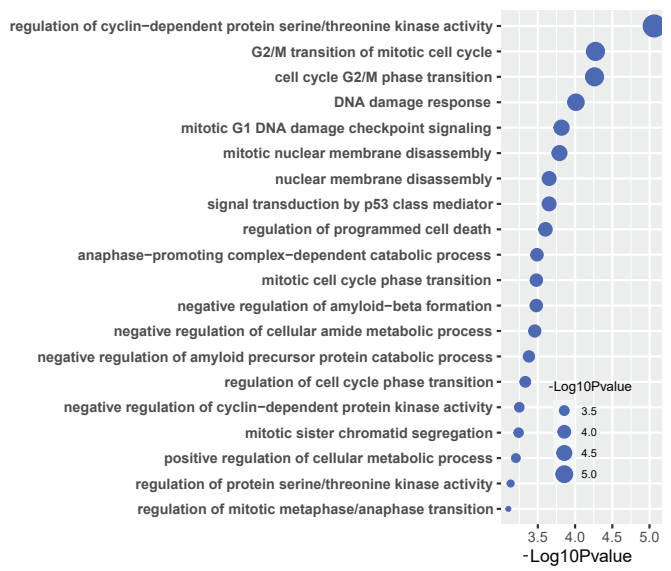

Figure 5: Pathway study of UV-mediated skin cancer using (A) KEGG, (B) BioCarta and (c) Reactome. The pathways generated from the DEGs by combined score was used to sort the term results (based on P-value) using $\mathrm{R}$ studio. 


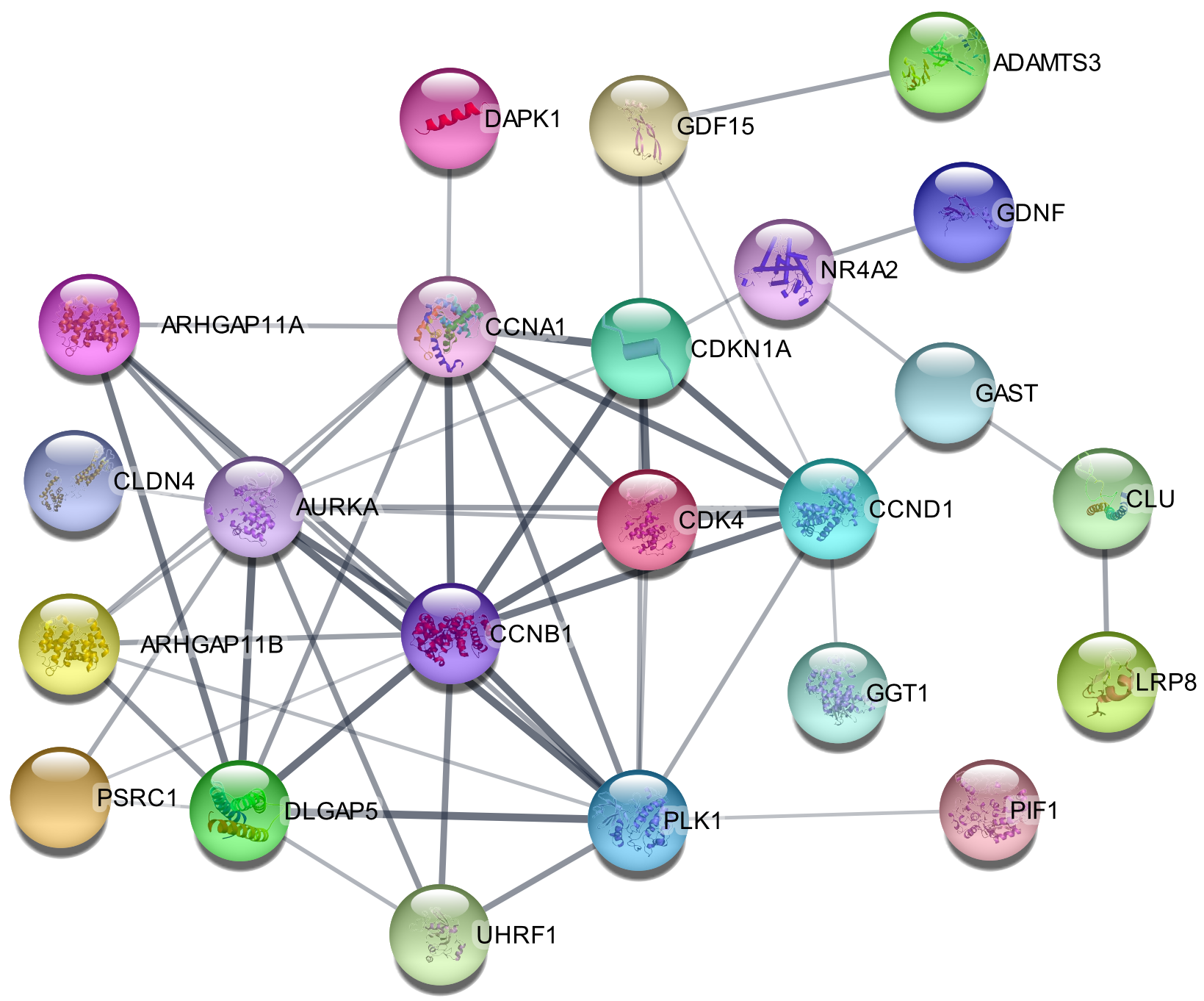

Figure 6: Visualization of the PPI network of skin cancer with 31 nodes and 58 edges. Nodes means proteins and the edges means the interaction of proteins. 


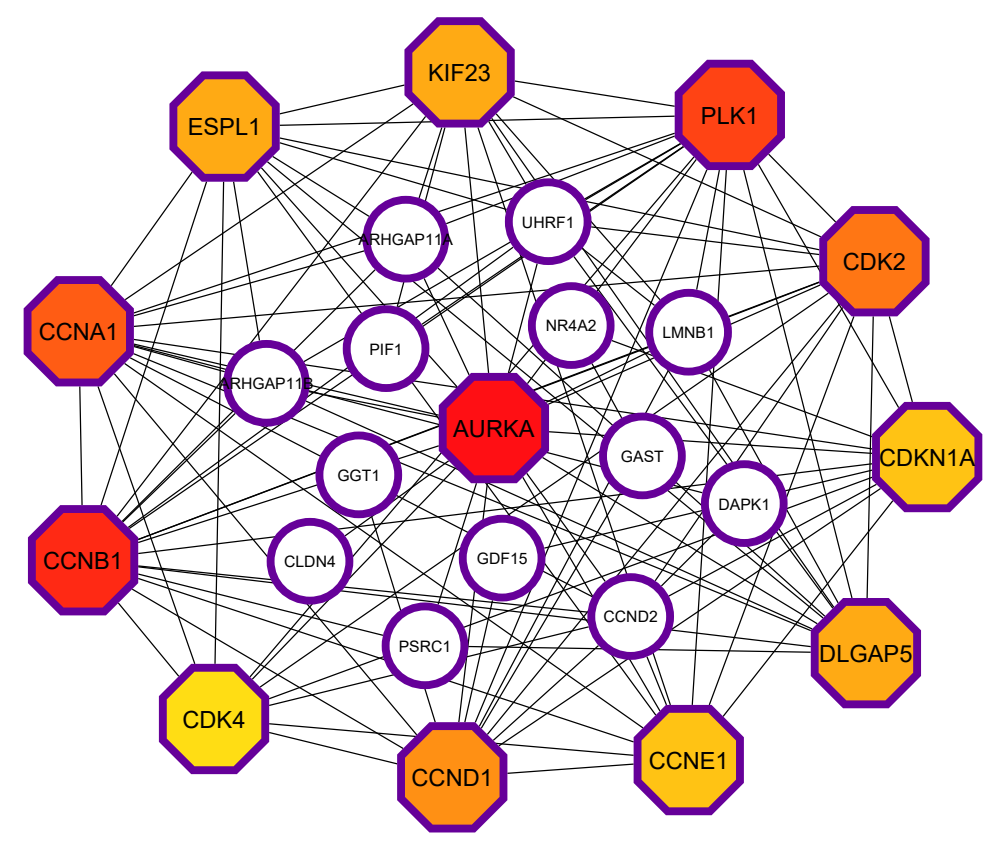

Figure 7: The simplified PPI network is built with the significantly dysregulated genes common to Skin cancer. The highlighted 12 nodes represent the hub genes.

applied Enrichr [31] with Fisher's exact test to run the functional enrichment analysis with the combined DEGs. Using a variety of databases, we evaluated the signaling pathways and gene ontologies associated with frequent DEGs. This over representation analysis identified a collection of enriched cell signalling pathways and functional GO keywords that show the biological importance of the identified DEGs. Molecular pathways were obtained from the databases such as Biocarta, Reactome and KEGG pathways, while gene ontologies were collected from biological process, cellular component, and molecular function databases. Only the significant pathways with a p-value less than 0.05 are examined after the duplicate pathways have been removed. The pathway and ontologies were showed in bubble plots that created using R Studio software.

\subsection{Establishment of PPI and Selection of Hub Genes}

The analysis of protein-protein interactions (PPI) provides information about the proteins and their connection. Considering the combined DEGs common among SC datasets, we created PPI networks to test our findings. Using the STRING 60] protein interactome database (provided 24,584,628 proteins from 5090 organisms), we were able to identify protein sub-networks. Then importing ".txt" to the ".csv" file into the Cytoscape [57, we generate a PPI network. In the PPI network, the number of nodes represents proteins while edges indicate interactions between proteins. PPI information was collected by mapping the hub genes, with high maximal clique centrality (MCC) values representing hub genes. To create the hub genes network, we used the cytohubba plugin of Cytoscape [5]. High-interaction proteins were discovered using topological metrics, such as an MCC algorithm is a topological metric, and its higher value indicates high interconnected proteins between PPI networks.

\subsection{Survival and Expression Profile analysis of Hub Genes}

Gene Expression Profiling Interactive Analysis (GEPIA2) enables quick and customized delivery of capabilities based on The Cancer Genome Atlas (TCGA) and genotype-tissue expression (GTEx) data to further study the influence of hub gene expression on patient clinical outcomes 62]. GEPIA2 analyzes DEGs in SC samples to determine the survival effect and to generate an expression profile. Using a median transcript per million (TPM), SC samples were classified into high and low expression hub gene groups. We calculated the log-rank p-value The overall survival effect of hub genes in SC was estimated by calculating the log-rank p-value $<0.05$ and the HR (hazard ratio-95 percent confidence interval) for hypothesis test using GEPIA2 single-gene analysis. On the other hand, the relative expression levels of the hub genes were selected based on the $\log _{2} F C$ cutoff value of $<1$, and the q-value Cutoff was $<$ 0.01. For the statistical significance of each hub gene, p-value $<0.05$ was considered in our analysis. In our study, a p-value $<0.05$ was considered significant for each hub gene. 

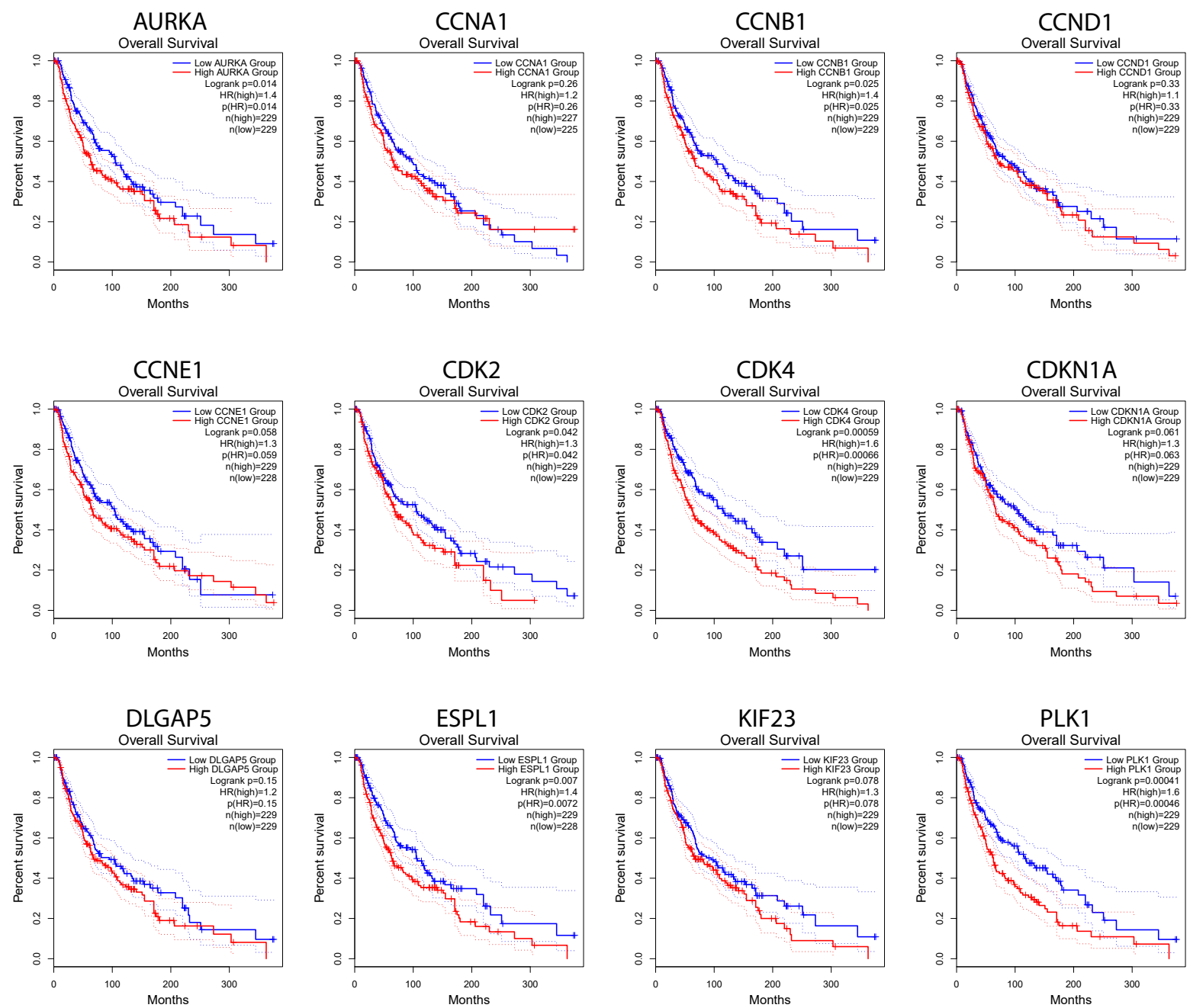

Figure 8: Kaplan-Meier overall survival analysis of the core hub genes expressed in Skin cancer. Curves were generated using Gene Expression Profiling Interactive Analysis based on The Cancer Genome Atlas database ( $\mathrm{p} \leq 0.01$ ). 

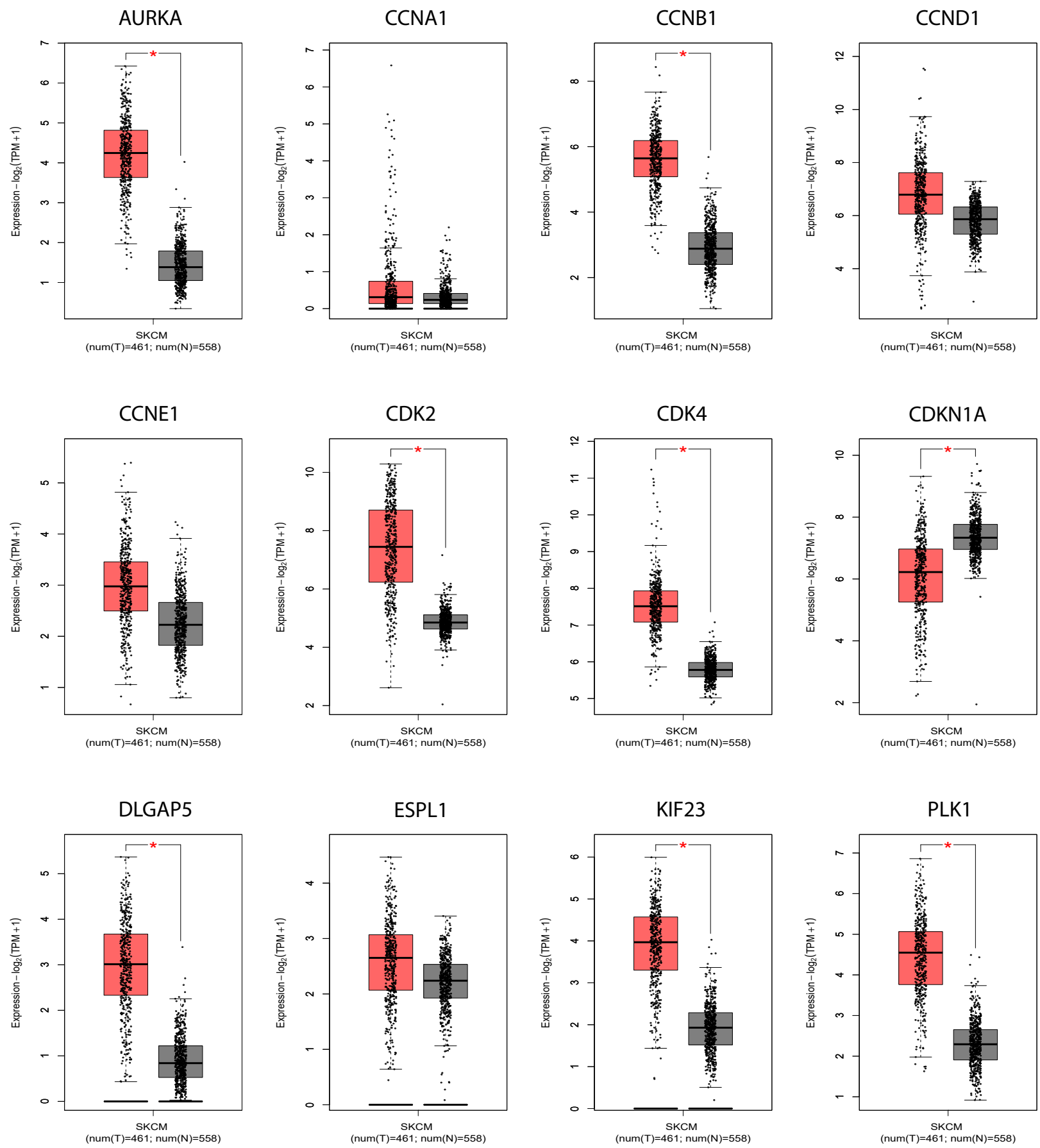

Figure 9: Relative expression levels of hub genes expressed in skin cancer. The GEPIA was used to verify the DEGs between normal and skin cancer tissues in the TCGA database. Red and black boxes represent the relative expression levels of genes in the tumor and normal samples, respectively. 
(A)

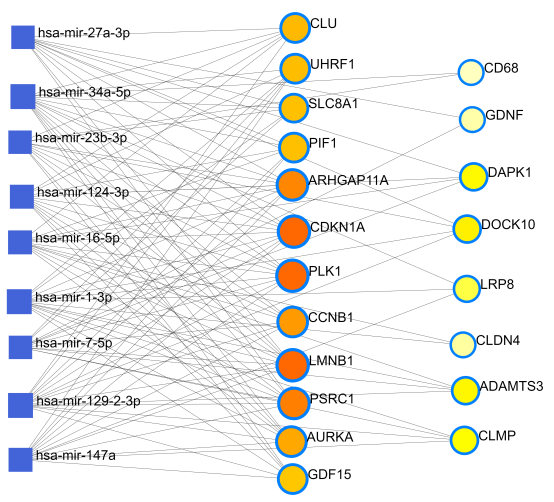

(C)

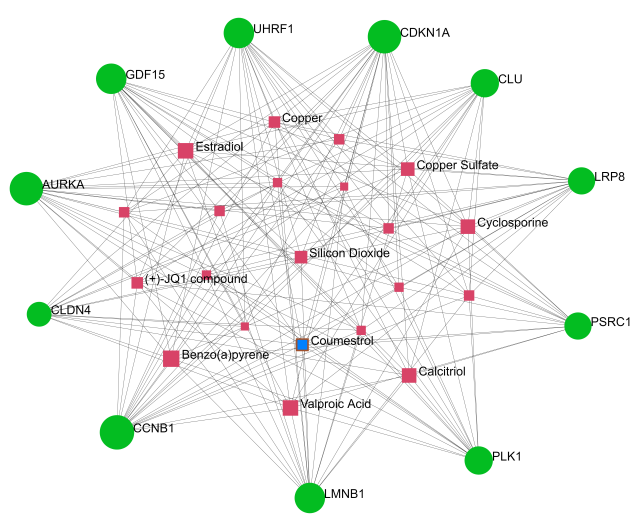

(B)

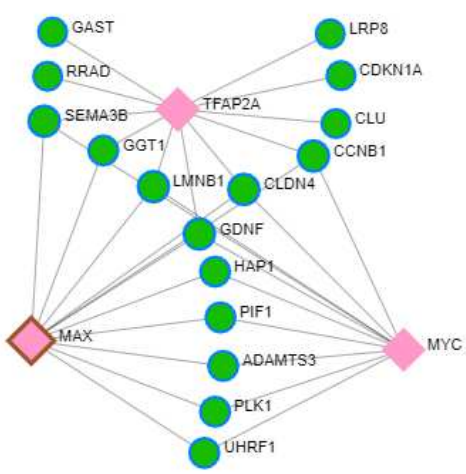

(D)

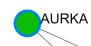

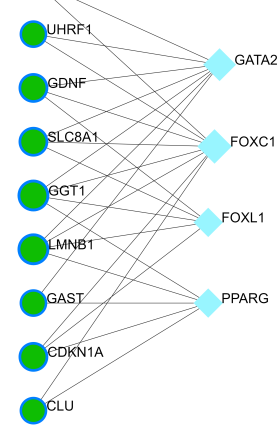

Figure 10: : GRN study identify the potential TFs and miRNAs through Network analyst. (A) The network of DEGs and miRNA. (B) The network of TFs and miRNAs. (C) Highly enriched interrelated chemical agents.(D) The network of TFs and DEGs. Circle represent DEGs, and square represent miRNAs and TFs. 


\subsection{Identification of Regulatory Biomolecules}

Transcriptional and post-transcriptional regulatory biomolecules like transcription factors (TFs) and microRNAs (miRNAs) may significantly alter how transcription and expression are processed. Using the Network Analyst platform, we can find DEGs-miRNAs and TFs-DEGs networks based on dysregulated genes that are shared among them. In order to explore DEGs-miRNAs interaction networks, the TarBase 42] database while the TFs-DEGs interaction network, the JASPAR [54 database is used. The DEGsTFs network was screened for TFs and the miRNA were selected from the DEGs-miRNAs network with a degree of 10 and a betweenness centrality value of 100 .

\subsection{Protein-Chemical Compound Analysis}

Analyses of protein-chemical compounds can be used to identify the chemical molecules responsible for the interaction of proteins in SC. Through the use of the enriched gene (common DEGs) among three groups of SC, the Comparative Toxicogenomics Database [9] was able to find protein-chemical interactions with the help of Network Analyst 69].

\section{Result}

\subsection{Identification of DEGs in SC Datasets}

The NCBI GEO database provided the SC RNA sequence data set GSE85443 for this study. Biojupies online server was used to find UV-responsive dysregulated gene of human skin squamous cell carcinoma (SCC). As a whole, the DEGs were found to meet the cutoff criteria $\left(\log _{2} f c>1\right.$ and p-value $\left.<0.05\right)$. We found 289, 620, and 649 DEGs in total through GSE85443 (N0), GSE85443 (N1), and GSE85443 (N2) subsets of GSE85443 dataset analysis, respectively (Table 1). The volcano plot in the Figure 2 was generated to compare the up and down-regulated genes. The number of shared DEGs between two groups of SC three datasets are presented in the Venn diagram (Figure $3 \mathrm{C}$ ). Then the 32 common DEGs were identified by comparing three subsets of a dataset and among these 19 up-regulated genes (i.e., CDKN1A, CDK4, CLDN4, CLU, RNR1 and SEMA3B etc.) and 13 down-regulated genes (i.e. AURKA, ADAMTS3, CCNB1, CLMP, DOCK10, LMNB1 and PLK1 etc.). The heat maps display the 32 DEGs that were common throughout three groups of the GSE85443 dataset and their connections based on an adjusted p-value and a $\log _{2}$ foldchange (Figure $3 \mathrm{~A}$ and $3 \mathrm{~B}$ ).

\subsection{Functional Enrichment Analysis Finds Significant GO Terms and Molecular Pathways}

Pathways and gene ontology (GO) was discovered by doing a gene set enrichment analysis on the overlapping DEGs to understand SC development better. An enrichment test on DEGs using the Enrichr tool allowed us to discover cell signalling pathways and three functional GO terms significantly enhanced with DEGs. For classifying functional categories, we looked for DEGs that were excessively represented in three different SC sub-datasets. The Figure 5 showed the top ten pathways for each disease with a p-value less than 0.05 as a reference. Gene ontology (GO) methods were used to categorize improved standard DEG sets into biological importance and molecular functions. To narrow GO terms, we used a statistical method with a p-value below 0.05. Among $30 \mathrm{GO}$ terms, progesterone-mediated oocyte maturation, cell cycle, phosphorylation of Emi1, activation of NIMA kinases NEK9, NEK6, NEK7, cyclin and cell cycle regulation and cell cycle: G2/M checkpoint were significant according to our analysis (Figure 4). The most significant molecular pathways in our study were found to the regulation of cyclin-dependent protein serine/threonine kinase activity, G2/M transition of the mitotic cell cycle, receptor-ligand activity, purine ribonucleoside triphosphate binding and cytoskeleton based on a $\log 10$ p-value (Figure 5).

\subsection{Identification PPI and Hub Genes}

We examined the STRING network and displayed it in Cytoscape using our gene sets for common illnesses to anticipate typical DEG linkages and adhesion pathways. A PPI network with 31 nodes and 58 edges was built using the interactions of common DEGs (Figure 6). As part of the organism's "interactomics," abnormal PPIs can lead to various health problems. If two diseases have one or more commonly linked in protein subnetworks, they have been connected. For the purpose of identifying the 12 central proteins including CDK4, CDKN1A, PLK1, CCND1, CDK2, AURKA, CCNA1, ESPL1, CCNB1, CCNE1, KIF23 and DLGAP5 from the PPI, we used the degree algorithm of the Cyto-Hubba plugin as shown in the Figure 7. Table 2 provided functional properties of the top 12 hub genes in the PPI network. 


\subsection{Survival and Expression Profile Analysis of Hub Genes}

Skin cancer samples were divided into two groups based on their median expression level of hub genes. Twelve hub genes from both the up and down-regulated DEGs were examined for their overall relationship with survival using the GEPIA survival assessment (Figure 8). Among the twelve hub genes AURKA, CDK2, CDK4, CCNB1, ESPL1 and PLK1 showed significantly lower overall survival in the higher group for considering p-value $<0.05$ and Hazard Ratio (HR). CDK4 and PLK1 showed a higher hazard ratio of about 1.6 which indicated the most survival proteins. However, based on the hub gene expression levels, we have identified that only one hub gene CDKN1A was up-regulated in normal cells and the other eleven hub genes were up-regulated in the tumor cells. Among 11 up-regulated genes AURKA, PLK1, CDK2, and DLGAP5 were higher expression levels in tumor tissue (Figure 9).

\subsection{Gene regulatory network study identified DEG-miRNA and TF-DEG interaction networks}

In all living organisms, TFs control transcription and gene expression levels. In addition, these proteins are essential for all aspects of cellular life [6]. Besides, small RNA molecules are known as microRNA (also known as miRNAs), control gene expression at the post-transcriptional level after transcription has taken replace. A new class of molecular regulators known as microRNAs (miRNA) has been discovered that controls several genes and pathways essential in the pathogenesis of SC 38 . We used DEGs that are common to three datasets of SC. The DEGs-TFs linkage networks were examined using a network-based approach to uncover transcriptional and post-transcriptional regulatory networks for common DEGs. The network of DEGs-miRNAs, TFs-miRNAs and DEGs-TFs interactions are depicted in Figure10 A, Figur 10 B, and Figure10D. In these figures, circles represent DEGs whereas squares represent miRNAs and TFs. The biomolecules including TFAP2A, FOXC1, GATA2, MAX, MYC, FOXL1 and PPARG were the most significant TFs regulators of the identified common DEGs. Several miRNAs, including mir-1-3p, mir-7-5p, mir-147a, mir-34a-5p, and mir-124-3p were significant which provide deep knowledge of the DEGs at post-transcriptional regulators. AURKA and PLK1 are significant genes in a network that connect multiple edges. Biomolecules involved in regulating gene transcription and post-transcriptional processes are included in the Table 3.

Table 1: The differentially expressed gene (DEG) for all employed Datasets in the present study

\begin{tabular}{|c|c|c|c|c|c|c|c|c|}
\hline Group & $\begin{array}{c}\text { Number } \\
\text { of } \\
\text { samples }\end{array}$ & $\begin{array}{l}\text { Disease } \\
\text { state }\end{array}$ & Tissue & Cell type & Organism & $\begin{array}{l}\text { Signature } \\
\text { genes }\end{array}$ & Up & Down \\
\hline \multirow[t]{2}{*}{$2^{*} \mathrm{GSE} 85443 \mathrm{~N} 0$} & 1 control & Non-irradiated control keratinocytes & \multirow[t]{2}{*}{$2^{*}$ Neonatal foreskin } & \multirow{2}{*}{$2^{*}$ Cultured primary keratinocytes } & \multirow{2}{*}{$2 *$ Homo sapiens } & \multirow{2}{*}{$2 * 289$} & \multirow{2}{*}{$2 * 152$} & \multirow{2}{*}{$2 * 137$} \\
\hline & 9 case & UV-irradiated human keratinocytes & & & & & & \\
\hline \multirow{2}{*}{$2^{*}$ GSE85443 N1 } & 1 control & Non-irradiated control keratinocytes & \multirow[t]{2}{*}{$2^{*}$ Neonatal foreskin } & \multirow{2}{*}{$2{ }^{*}$ Cultured primary keratinocytes } & \multirow[t]{2}{*}{$2^{*}$ Homo sapiens } & \multirow[t]{2}{*}{$2 * 620$} & \multirow[t]{2}{*}{$2 * 345$} & \multirow[t]{2}{*}{$2 * 275$} \\
\hline & 6 case & UV-irradiated human keratinocytes & & & & & & \\
\hline \multirow[t]{2}{*}{$2^{*}$ GSE $85443 \mathrm{~N} 2$} & 1 control & Non-irradiated control keratinocytes & \multirow[t]{2}{*}{$2 *$ Neonatal foreskin } & \multirow[t]{2}{*}{$2 *$ Cultured primary keratinocytes } & \multirow[t]{2}{*}{$2 *$ Homo sapiens } & \multirow[t]{2}{*}{$2 * 649$} & \multirow[t]{2}{*}{$2^{*} 278$} & \multirow[t]{2}{*}{$2^{*} 371$} \\
\hline & 6 case & UV-irradiated human keratinocytes & & & & & & \\
\hline
\end{tabular}

Table 2: Summary of hub genes identified by protein-protein interaction analysis encoded by DEGs that are common to three groups of UV-mediated skin cancer.

\begin{tabular}{|l|l|l|l|l|}
\hline Hub genes name & Description & MCC value & Features & Uniprot ID \\
\hline CDK2 & Cyclin-dependent kinase-2 & 105960 & $\begin{array}{l}\text { Involved in the control } \\
\text { of the cell cycle }\end{array}$ & P24941 \\
\hline CCNE1 & G1/S-specific cyclin-E1 & 90720 & $\begin{array}{l}\text { Essential for the regulation of } \\
\text { the cell cycle at the G1/S transition }\end{array}$ & P24864 \\
\hline CCND1 & G1/S-specific cyclin-D1 & 80764 & Regulates the cell cycle during G1/S transition & P24385 \\
\hline CDK4 & Cyclin-dependent kinase-4 & 85680 & Regulates the cell cycle during G1/S transition & P11802 \\
\hline CDKN1A & Cyclin-dependent kinase inhibitor 1 & 80643 & $\begin{array}{l}\text { Involved in p53/TP53 mediated inhibition of } \\
\text { cellular proliferation in response to DNA damage }\end{array}$ & P38936 \\
\hline PLK1 & Serine/threonine-protein kinase PLK1 & 71402 & $\begin{array}{l}\text { Regulating the centrosome maturation } \\
\text { and spindle assembly }\end{array}$ & $\begin{array}{l}\text { Required for the myosin contractile ring formation } \\
\text { during the cell cycle cytokinesis }\end{array}$ \\
\hline KIF23 & Kinase-like protein KIF23 & 25202 & $\begin{array}{l}\text { Role in the chromosome segregation during } \\
\text { the cell cycle process }\end{array}$ & Q14674 \\
\hline ESPL1 & Separin & 25920 & 111726 & $\begin{array}{l}\text { Essential for the control of the cell cycle } \\
\text { at the G2/M transition }\end{array}$ \\
\hline CCNB1 & Cyclin-A1 & 101522 & $\begin{array}{l}\text { Controlling of the mitotic cell cycle in } \\
\text { some somatic cell. }\end{array}$ \\
\hline CCNA1 & Disks-large-associated protein-5 & 20886 & $\begin{array}{l}\text { Cell cycle regulator that may play role in } \\
\text { carcinogenesis of cancer cells }\end{array}$ \\
\hline DLGAP5 & Aurora kinase A & 111727 & $\begin{array}{l}\text { Contributes to the regulation of cell } \\
\text { cycle progression }\end{array}$ & P14635 \\
\hline AURKA & & Q15396 \\
\hline
\end{tabular}




\subsection{Analyzing Protein-Chemical Compounds Reveals Protein-Chemical Interactions}

For the purpose of discovering new drugs, knowing how proteins underlie cellular and molecular processes are critical in the field of protein-chemical interaction research. Several proteins are interconnected to chemical interaction networks of SC which have found in our study. We discovered several potentially interrelated chemical compounds including valproic acid, coumestrol, estradiol, copper sulfate, calcitriol, cyclosporine and benzo (a) pyrene, among highly enriched chemical agents (Figure10 C). This network can also identify significant proteins such as AURKA, PLK1, CCNB1, CDKN1A, UHRF1, CLU, LMNB1, CLDN4, PSRC1, LRP8 and GDF15.

\section{Discussion}

The prognosis for early-stage SC is much better than for advanced-stage. Early skin cancer detection is essential and can prevent some cancers such as focal cell carcinoma and melanoma. Surgery, chemo-radiation, or a combination of treatments were effective in curing early-stage instances. Still CC patients in the advanced stages suffered more because of recurrences and the disease's incurable nature. Advanced-stage CC patients suffered the most because of recurrences and the incurable nature of the disease [3. We employed several bioinformatics approaches to evaluate RNA-Seq datasets based on the NCBI-GEO database, comprising $21 \mathrm{UV}$ - irradiated human keratinocytes tissue and three non-irradiated human keratinocytes tissue to find potential predictive biomarkers in skin cancer. Using the GEO2R online tool and Venn software, a set of 32 DEGs were found including 19 genes that were found to be up-regulated and 13 down-regulated genes. After that, GO and signalling pathway analysis was performed with the findings showed that they were highly enriched in a variety of cell systems. According to the pathway assessment, metabolic responses and cell cycle regulation accounted for most pathways responsible for pathogenesis and progression of UV-mediated skin cancer. After, further enrichment performed on the DEGs, we have discovered some noteworthy GOs. Regulation of cyclin-dependent protein serine/threonine kinase activity (GO: 0000079) and G2/M transition of the mitotic cell cycle (GO: 0000086) for biological process. Spindle microtubule (GO: 0005876) and cytoskeleton (GO: 0005856) for the cellular component. Receptor ligand activity (GO: 0048018) and cyclin-dependent protein serine/threonine kinase regulator activity (GO: 0016538) for respectively to molecular function. Regulation of cyclin-dependent protein serine/threonine kinase activity (GO: 0000079): Haidan Liu et al. suggested that inhibition of CDK4 and CDK2 in cell cycle regulator can be targeted as a molecular marker in skin cancer 35. Cytoskeleton (GO: 0005856): Actin cytoskeleton was modulated by downregulating the AC-cAMP pathway; both collectively lead to skin carcinoma progression 2. Receptor ligand activity (GO: 0048018): The result indicated that receptors (Eph) and ligand (ephrin) represent a new potential prognostic marker and therapeutic target in non-melanoma skin cancer [21. From the molecular pathway analysis, we have found progesterone-mediated oocyte maturation and cell cycle for KEGG. Cell Cycle: G2/M checkpoint pathway and cell cycle regulation for biocarta analysis. Phosphorylation of Emi1 and activation of NIMA kinases NEK9, NEK6, NEK7 for Reactome. Progesterone-mediated oocyte maturation: Yumei Li et al. concluded that the progesterone-mediated oocyte maturation pathway is involved in melanoma metastasis through bioinformatics analysis 34. Cell cycle: Thomas M. Runger et al. demonstrated that regulation of cell cycle checkpoints and DNA repair is responsible for UV mediated skin cancer [53][47]. Activation of NIMA Kinases like NEK9, NEK6, and NEK7 is responsible for CDK and PLK1 mediated phosphorylation [50. Further, the string database was used to build the PPI network. The combined PPI analysis using Cytoscape revealed 12 hub genes based on degree value, clustering coefficient, betweenness centrality, and closeness centrality. These 12 hub genes CDK4, CDKN1A, PLK1, CCND1, CDK2, AURKA, CCNA1, ESPL1, CCNB1, CCNE1, KIF23 and DLGAP5 had diagnostic value which distinguishes SC patients apart from the rest of the population; having the ability to discriminate between people with skin cancer and healthy individuals as a diagnostic marker. Cyclin-dependent kinases 4 (CDK4) trigger a G1 arrest by playing important roles in the control of the cell cycle 63] and are overexpressed in human skin cancers [59]. During the first gap phase (G1 to $\mathrm{S}$ ) of the cell cycle, CDK4 inhibitors keep everything under control [18]; in addition, over 90 percent of people with melanoma had genetic abnormalities in the CDK4 pathway [58. Cyclin-dependent kinase inhibitor 1 (CDKN1A) was downregulated in melanomas, suggesting a possible involvement in carcinogenesis [70. Raising the polo-like kinase 1 (PLK1) expression in human melanoma like BCC and SCC is considerably overexpressed. There was also a considerable G2/M cell cycle arrest, mitotic catastrophe and induce apoptosis in melanoma cells when PLK1 was found to be anti-proliferative [55]. The expression of G1/S-specific cyclin-D1 (CCND1) mRNA genes and proteins is associated with the development of SC [14, which may be altered by mutations in BRAF and NRAS [66]. G1/S and S/G2 
transitions are controlled by cyclin-dependent kinase 2 (CDK2) which helps melanomas cells aggressive by regulating CDK2 expression [44]57]. Aurora kinase A (AURKA) is a key protein in controlling the G2 to $\mathrm{M}$ transition in mitosis and may serve as an oncogene [8]. Cell cycle regulation during the G1/S and G2/M transition in certain somatic cells is thought to be mediated by cyclin-A1 (CCNA1) protein 22 . There is evidence to suggest that separase autocleavage or the cleaved fragments play an essential role in cell cycle progression when extra spindle pole bodies like 1 (ESPL1) protein is present [72]. Following quantitative real-time reverse transcriptase-PCR analysis of the major target genes PTCH1, GLI1, GLI2 and CCNB1; in both normal a malignant skin, the average E3 ubiquitin ligase CCNB1Ip1 (CCNB1) transcript level was the same between the two groups [29]. G1/S-specific cyclin-E1 (CCNE1) increase may be a significant biomarker for patients with acral melanoma to predict treatment success 68. Microtubule-dependent and Rho-mediated signalling are necessary for developing the myosin contractile ring during cell cycle cytokinesis and kinesin-like protein (KF23) fulfils this purpose [28]. A potential cell cycle regulator, disks large-associated protein 5 (DLGAP5) may have a role in developing cancer cells including their carcinogenesis [11. AURKA, CDK2, CDK4, CCNB1, ESPL1 and PLK1 showed a significant survival rate in the group with greater levels of expression, while AURKA PLK1, CDK2, and DLGAP5 were found in higher expression levels in tumor tissue. Additionally, CDK4 has immune-modulatory properties and inhibiting CDK4 via the reduction of NFAT family members can significantly increase $\mathrm{T}$ cell activation 11. Anti-melanoma immune checkpoint drugs can slow tumor development by decreasing CDK4/6 activity, slowing the resistance pathway and inducing senescence 25]. Melanoma patients who have resisted anti-PD-1 treatment had evident CDK4 pathway abnormalities including CDKN2A loss, CDK4 and CCND1 gain which were confirmed through the whole genome and RNA sequencing profiling studies 71 . X. Wu et al. studies established a rationale for treating acral melanoma using CDK inhibitors 68. Melanoma preclinical trials using CDK4/6 inhibition along with genetic analysis for the pathway give a foundation for treating various diseases with targeted agents. An in-vitro investigation done by T. Schmit et al. found that PLK1 is overexpressed in both protein and mRNA levels in SCC (A253 and A431) relative to normal keratinocytes (NHEK) [55. As a therapeutic target for cSCC and PLK1 has the advantage of already having numerous small molecule inhibitors in clinical trials [56, 10. These findings add together to show that cSCC treatment focusing on PLK1 holds a lot of potentials. Aurora kinase and FOXM1 proteins play a crucial role in melanoma formation implying that AURKA expression affects disease prognosis [48. As AURKA is highly expressed in melanomas, inhibiting it may have the effect of slowing tumor growth indicates the development of new therapies of SC treatment 4. Table 3 showed the detailed information of identified 7 TFs that regulate transcriptional activity during tumor cell proliferation. Only GATA2 was shown to be unrelated to the development of skin cancer in our investigation, as verified by literature analysis. We also found several miRNAs molecules; among these mir-7-5p has anti-tumor effects via preventing melanoma cell invasion and migration [16; and mir-34a-5p suppresses cell proliferation in melanoma cell [33. In treating head and neck squamous cell carcinoma, valproic acid (VPA) has shown effectiveness was confirmed by R. B. Erlich et al. studies [13; VPA sensitisation effects can be used to target drug resistance in melanoma cells [27. Preconditioning skin cancers with calcitriol (the active form of Vitamin D) before ALA-PDT dramatically enhances treatment outcomes, according to K. Rollakanti, S. Anand, and E. V Maytin studies [51. G. Park et al. demonstrated that a new dietary component coumestrol may help prevent and treat UVB-induced skin cancer [43. Cyclosporine A lessens skin cancer cell death in transplant patients by inhibiting MPTP in a model of the disease's occurrence in keratinocytes [39]. The pathway analysis recommended that the regulation of cyclin-dependent protein serine/threonine kinase activity, cytoskeleton pathway, receptor-ligand activity and the cell cycle regulator were the most significant pathways for inhibiting the expression of associated genes. Selection of hub genes from PPI, survival and expression level analysis of hub genes, GRN studies and protein-chemical interaction analysis indicated that AURKA, PLK1 and CDK4 could be served as the most potential biomarker in skin cancer therapy. The GATA2 transcription factors may also serve as novel biomarkers in the treatment of skin cancer. Several miRNAs identified in our study, including mir-7-5p, and mir 34a-5p are all candidates for therapeutic intervention in melanomas because of their roles in tumor growth and progression. Valproic acid, coumestrol, calcitriol and Cyclosporine A were indicated the potential therapeutic agent in a melanoma cell. These findings expand our understanding of UV-induced skin tumorigenesis and tumor progression and suggest targeting AURKA, CDK4, and PLK1 genes can help prevent or treat UV-associated skin cancer. 


\section{Conclusions}

The emergence of omics methods has given bioinformatics a substantial boost in recent decades. Several gene expression changes are linked with human cancer, and the RNA sequence is one of the most commonly utilized omics techniques for their detection. When it comes to diagnosing cancer, the most frequently utilized omics technique is using RNA sequences to uncover the myriad of gene expression alterations linked with various types of human malignancies. RNA sequence data was used in this work to examine the transcriptome of a collection of UV-irradiated human keratinocyte lesions using a constrained pipeline method; we were able to separate 21 different case states from the merging of three sub-datasets of SC by using 32 common DEGs. Three differential genes (AURKA, CDK4 and PLK1) were identified through gene ontology and molecular pathway, protein-protein interaction, survival and expression analysis, gene-regulatory network and protein-chemical interactions. Based on findings and explanations in this study, the AURKA, CDK4 and PLK1 genes have been identified as viable biomarkers for skin cancer in mostly metabolic and cell cycle regulatory pathways. According to our findings, these three genes should serve as possible biomarkers for the early identification of UV-mediated SC. The AURKA, CDK4 and PLK1 proteins expression need to be validated as clinical biomarkers through further investigational and experimental approaches to understand the pathological process better and anticipate UV-irradiated SC diagnosis.

Table 3: Summary of transcriptional and post-transcriptional regulatory biomolecules of DEGs overlapped among three groups of UV-mediated skin cancer that includes (a) Regulatory Transcription Factors and (b) Regulatory microRNAs

\begin{tabular}{|c|c|c|c|c|}
\hline \multicolumn{5}{|c|}{ (a) Regulatory Transcription Factors } \\
\hline TFs name & \multicolumn{2}{|l|}{ Description } & Function & Type \\
\hline FOXC1 & \multicolumn{2}{|l|}{ Forkhead Box C1 } & $\begin{array}{l}\text { NA-binding transcription factor } \\
\text { activity and transcription factor binding }\end{array}$ & Stress-responsive \\
\hline GATA2 & \multicolumn{2}{|l|}{ GATA binding protein 2} & $\begin{array}{l}\text { DNA-binding transcription factor } \\
\text { activity and chromatin binding }\end{array}$ & Oxidative stress-responsive \\
\hline MYC & \multicolumn{2}{|l|}{ Myc Proto-Oncogene } & $\begin{array}{l}\text { Regulating numerous biological activities } \\
\text { that contribute to tumorigenesis }\end{array}$ & Cell cycle regulator \\
\hline TFAP2A & \multicolumn{2}{|c|}{ Transcription Factor AP-2 Alpha } & $\begin{array}{l}\text { DNA-binding transcription factor activity } \\
\text { and sequence-specific DNA binding }\end{array}$ & DNA regulator \\
\hline MAX & \multicolumn{2}{|l|}{ Myc-associated factor X } & $\begin{array}{l}\text { Regulating numerous biological activities } \\
\text { that contribute to tumorigenesis }\end{array}$ & Cell cycle regulator \\
\hline FOXL1 & \multicolumn{2}{|l|}{ Forkhead Box L1 } & $\begin{array}{l}\text { NA-binding transcription factor activity } \\
\text { and DNA-binding transcription factor activity }\end{array}$ & Stress-responsive \\
\hline \multirow[t]{7}{*}{ PPARG } & \multicolumn{2}{|c|}{ Peroxisome Proliferator Activated Receptor Gamma } & $\begin{array}{l}\text { DNA-binding transcription factor activity } \\
\text { and chromatin binding }\end{array}$ & DNA regulator \\
\hline & \multicolumn{3}{|c|}{ (b)Regulatory microRNAs } & \\
\hline & miRNA Name & Description & Function & \\
\hline & hsa - mir-1-3p & MicroRNA 1 & $\begin{array}{l}\text { Suppresses the proliferation } \\
\text { and invasion of cancer cells }\end{array}$ & \\
\hline & hsa - mir-7-5p & MicroRNA 7 & $\begin{array}{l}\text { Inhibits melanoma cell } \\
\text { migration and invasion }\end{array}$ & \\
\hline & hsa - mir-34a-5p & MicroRNA $34 a$ & $\begin{array}{l}\text { Suppresses cell proliferation } \\
\text { in melanoma cells }\end{array}$ & \\
\hline & hsa - mir-124-3p & MicroRNA 124 & $\begin{array}{l}\text { Leads to malignant progression } \\
\text { of cancer, including cell apoptosis, } \\
\text { migration and invasion }\end{array}$ & \\
\hline
\end{tabular}

\section{Acknowledgements}

This work was supported in part by the Department of Biotechnology and Genetic Engineering, Mawlana Bhashani Science and Technology University, and in part by the Department of Computer Science and Engineering (CSE), Islamic University, Kushtia-7003, Bangladesh.

\section{Funding Info}

There is no funding in our work.

\section{Ethics statement}

The authors have no relevant financial or non-financial interests to disclose. 


\section{Consent to participate and for publication}

Informed consent was obtained from all individual participants included in the study.

\section{Authors' contributions}

Md. Arju Hossain: Conceptualization, Methodology, Software, Data curation \& Writing. Asif Ahsan: Software, Validation, Writing - Original draft preparation \& editing. Md. Imran Hasan: Methodology, Software, Data curation, Validation \& Writing. Md. Arif khan: Data curation \& Writing. Md Sipon Miah: Data curation, Validation, reviewing \& editing. Md Habibur Rahman: Review \& editing.

\section{Availability of data and material}

The data that supports the findings of this study are openly available in NCBI.

\section{References}

[1] , . Cyclooxygenase-2 expression in murine and human nonmelanoma skin cancers: Implications for therapeutic approaches $\mathbb{I}$.

[2] Ahmed, M.B., Islam, S.U., Lee, Y.S., 2021. Prp4 promotes skin cancer by inhibiting production of melanin, blocking influx of extracellular calcium, and remodeling cell actin cytoskeleton. International Journal of Molecular Sciences 22, 6992.

[3] Bray, F., Ferlay, J., Soerjomataram, I., Siegel, R.L., Torre, L.A., Jemal, A., 2018. Global cancer statistics 2018: Globocan estimates of incidence and mortality worldwide for 36 cancers in 185 countries. CA: a cancer journal for clinicians $68,394-424$.

[4] Caputo, E., Miceli, R., Motti, M.L., Taté, R., Fratangelo, F., Botti, G., Mozzillo, N., Carriero, M.V., Cavalcanti, E., Palmieri, G., et al., 2014. Aurka inhibitors enhance the effects of b-raf and mek inhibitors in melanoma treatment. Journal of translational medicine 12, 1-9.

[5] Chen, S.H., Chin, C.H., Wu, H.H., Ho, C.W., Ko, M.T., Lin, C.Y., 2009. cyto-hubba: A cytoscape plug-in for hub object analysis in network biology, in: 20th International Conference on Genome Informatics, Citeseer.

[6] Cheng, C., Alexander, R., Min, R., Leng, J., Yip, K.Y., Rozowsky, J., Yan, K.K., Dong, X., Djebali, S., Ruan, Y., et al., 2012. Understanding transcriptional regulation by integrative analysis of transcription factor binding data. Genome research 22, 1658-1667.

[7] Consortium, G.O., 2015. Gene ontology consortium: going forward. Nucleic acids research 43, D1049-D1056.

[8] Cox, D.G., Hankinson, S.E., Hunter, D.J., 2006. Polymorphisms of the aurka (stk15/aurora kinase) gene and breast cancer risk (united states). Cancer Causes \& Control 17, 81-83.

[9] Davis, A.P., Grondin, C.J., Johnson, R.J., Sciaky, D., McMorran, R., Wiegers, J., Wiegers, T.C., Mattingly, C.J., 2019. The comparative toxicogenomics database: update 2019. Nucleic acids research 47, D948-D954.

[10] Degenhardt, Y., Lampkin, T., 2010. Targeting polo-like kinase in cancer therapy. Clinical cancer research 16, 384-389.

[11] Deng, J., Wang, E.S., Jenkins, R.W., Li, S., Dries, R., Yates, K., Chhabra, S., Huang, W., Liu, H., Aref, A.R., et al., 2018. Cdk4/6 inhibition augments antitumor immunity by enhancing t-cell activation. Cancer discovery 8, 216-233.

[12] Diepgen, T.L., Mahler, V., 2002. The epidemiology of skin cancer. British Journal of Dermatology 146, 1-6. 
[13] Erlich, R.B., Rickwood, D., Coman, W.B., Saunders, N.A., Guminski, A., 2009. Valproic acid as a therapeutic agent for head and neck squamous cell carcinomas. Cancer chemotherapy and pharmacology 63, 381-389.

[14] Eshkoor, S.A., 2007. Expression of CCND1, P16 and CDK6 in Human Basal Cell Carcinoma. Ph.D. thesis. Universiti Putra Malaysia.

[15] Gilchrest, B.A., Eller, M.S., Geller, A.C., Yaar, M., 1999. The pathogenesis of melanoma induced by ultraviolet radiation. New England Journal of Medicine 340, 1341-1348.

[16] Giles, K.M., Brown, R.A., Epis, M.R., Kalinowski, F.C., Leedman, P.J., 2013. mirna-7-5p inhibits melanoma cell migration and invasion. Biochemical and biophysical research communications 430, 706-710.

[17] Glanz, K., Buller, D.B., Saraiya, M., 2007. Reducing ultraviolet radiation exposure among outdoor workers: state of the evidence and recommendations. Environmental Health 6, 1-11.

[18] Goel, S., DeCristo, M.J., McAllister, S.S., Zhao, J.J., 2018. Cdk4/6 inhibition in cancer: beyond cell cycle arrest. Trends in cell biology 28, 911-925.

[19] Gordon, R., 2013. Skin cancer: an overview of epidemiology and risk factors, in: Seminars in oncology nursing, Elsevier. pp. 160-169.

[20] Grossman, D.C., Curry, S.J., Owens, D.K., Barry, M.J., Caughey, A.B., Davidson, K.W., Doubeni, C.A., Epling, J.W., Kemper, A.R., Krist, A.H., et al., 2018. Behavioral counseling to prevent skin cancer: Us preventive services task force recommendation statement. Jama 319, 1134-1142.

[21] Hafner, C., Becker, B., Landthaler, M., Vogt, T., 2006. Expression profile of eph receptors and ephrin ligands in human skin and downregulation of epha1 in nonmelanoma skin cancer. Modern pathology 19, 1369-1377.

[22] He, X., Li, S., Shi, W., Lin, Q., Ma, J., Liu, Y., Feng, T., Cao, X., 2019. Cyclin a1 is associated with poor prognosis in oesophageal squamous cell carcinoma. Oncology letters 18, 706-712.

[23] Higashi, Y., Kanekura, T., Kanzaki, T., 2000. Enhanced expression of cyclooxygenase (cox)-2 in human skin epidermal cancer cells: Evidence for growth suppression by inhibiting cox-2 expression. International journal of cancer 86, 667-671.

[24] Iordanov, M.S., Choi, R.J., Ryabinina, O.P., Dinh, T.H., Bright, R.K., Magun, B.E., 2002. The uv (ribotoxic) stress response of human keratinocytes involves the unexpected uncoupling of the rasextracellular signal-regulated kinase signaling cascade from the activated epidermal growth factor receptor. Molecular and cellular biology 22, 5380-5394.

[25] Jerby-Arnon, L., Shah, P., Cuoco, M.S., Rodman, C., Su, M.J., Melms, J.C., Leeson, R., Kanodia, A., Mei, S., Lin, J.R., et al., 2018. A cancer cell program promotes t cell exclusion and resistance to checkpoint blockade. Cell 175, 984-997.

[26] Jin, L., Zuo, X.Y., Su, W.Y., Zhao, X.L., Yuan, M.Q., Han, L.Z., Zhao, X., Chen, Y.D., Rao, S.Q., 2014. Pathway-based analysis tools for complex diseases: a review. Genomics, proteomics \& bioinformatics 12, 210-220.

[27] Kalal, B.S., Pai, V.R., Behera, S.K., Somashekarappa, H.M., 2019. Hdac2 inhibitor valproic acid increases radiation sensitivity of drug-resistant melanoma cells. Medical Sciences 7, 51.

[28] Kamijo, K., Ohara, N., Abe, M., Uchimura, T., Hosoya, H., Lee, J.S., Miki, T., 2006. Dissecting the role of rho-mediated signaling in contractile ring formation. Molecular biology of the cell 17, $43-55$.

[29] Kang, H.C., Wakabayashi, Y., Jen, K.Y., Mao, J.H., Zoumpourlis, V., Del Rosario, R., Balmain, A., 2013. Ptch1 overexpression drives skin carcinogenesis and developmental defects in k14ptchfvb mice. Journal of Investigative Dermatology 133, 1311-1320. 
[30] Kitagawa, D., Tanemura, S., Ohata, S., Shimizu, N., Seo, J., Nishitai, G., Watanabe, T., Nakagawa, K., Kishimoto, H., Wada, T., et al., 2002. Activation of extracellular signal-regulated kinase by ultraviolet is mediated through src-dependent epidermal growth factor receptor phosphorylation: its implication in an anti-apoptotic function. Journal of Biological Chemistry 277, 366-371.

[31] Kuleshov, M.V., Jones, M.R., Rouillard, A.D., Fernandez, N.F., Duan, Q., Wang, Z., Koplev, S., Jenkins, S.L., Jagodnik, K.M., Lachmann, A., et al., 2016. Enrichr: a comprehensive gene set enrichment analysis web server 2016 update. Nucleic acids research 44, W90-W97.

[32] Leite, G.G.F., Scicluna, B.P., van Der Poll, T., Salomão, R., 2019. Genetic signature related to heme-hemoglobin metabolism pathway in sepsis secondary to pneumonia. NPJ systems biology and applications 5, 1-9.

[33] Li, F., Li, X., Qiao, L., Liu, W., Xu, C., Wang, X., 2019. Malat1 regulates mir-34a expression in melanoma cells. Cell death \& disease 10, 1-11.

[34] Li, Y., Li, B., Chen, F., Shen, W., Katanaev, V.L., et al., 2020. Identification of core genes and pathways in melanoma metastasis via bioinformatics analysis .

[35] Liu, H., Liu, K., Huang, Z., Park, C.M., Thimmegowda, N., Jang, J.H., Ryoo, I.J., He, L., Kim, S.O., Oi, N., et al., 2013. A chrysin derivative suppresses skin cancer growth by inhibiting cyclindependent kinases. Journal of Biological Chemistry 288, 25924-25937.

[36] Lomas, A., Leonardi-Bee, J., Bath-Hextall, F., 2012. A systematic review of worldwide incidence of nonmelanoma skin cancer. British Journal of Dermatology 166, 1069-1080.

[37] Moon, J.S., Oh, C.H., 2001. Solar damage in skin tumors: quantification of elastotic material. Dermatology 202, 289-292.

[38] Neagu, M., Constantin, C., Cretoiu, S.M., Zurac, S., 2020. mirnas in the diagnosis and prognosis of skin cancer. Frontiers in cell and developmental biology 8, 71.

[39] Norman, K.G., Canter, J.A., Shi, M., Milne, G.L., Morrow, J.D., Sligh, J.E., 2010. Cyclosporine a suppresses keratinocyte cell death through mptp inhibition in a model for skin cancer in organ transplant recipients. Mitochondrion 10, 94-101.

[40] Oany, A.R., Mia, M., Pervin, T., Hasan, M.N., Hirashima, A., 2018. Identification of potential drug targets and inhibitor of the pathogenic bacteria shigella flexneri 2 a through the subtractive genomic approach. In silico pharmacology 6, 1-16.

[41] Oany, A.R., Mia, M., Pervin, T., Junaid, M., Hosen, S.Z., Moni, M.A., 2020. Design of novel viral attachment inhibitors of the spike glycoprotein (s) of severe acute respiratory syndrome coronavirus2 (sars-cov-2) through virtual screening and dynamics. International journal of antimicrobial agents $56,106177$.

[42] Papadopoulos, G.L., Reczko, M., Simossis, V.A., Sethupathy, P., Hatzigeorgiou, A.G., 2009. The database of experimentally supported targets: a functional update of tarbase. Nucleic acids research 37, D155-D158.

[43] Park, G., Baek, S., Kim, J.E., Lim, T.g., Lee, C.C., Yang, H., Kang, Y.G., Park, J.S., Augustin, M., Mrosek, M., et al., 2015. Flt3 is a target of coumestrol in protecting against uvb-induced skin photoaging. Biochemical pharmacology 98, 473-483.

[44] Peng, C., Zeng, W., Su, J., Kuang, Y., He, Y., Zhao, S., Zhang, J., Ma, W., Bode, A.M., Dong, Z., et al., 2016. Cyclin-dependent kinase 2 (cdk2) is a key mediator for egf-induced cell transformation mediated through the elk4/c-fos signaling pathway. Oncogene 35, 1170-1179.

[45] Pontén, F., Berne, B., Ren, Z.P., Nistér, M., Pontén, J., 1995. Ultraviolet light induces expression of p53 and p21 in human skin: effect of sunscreen and constitutive p21 expression in skin appendages. Journal of Investigative Dermatology 105, 402-406.

[46] Preston, D.S., Stern, R.S., 1992. Nonmelanoma cancers of the skin. New England Journal of Medicine 327, 1649-1662. 
[47] Prieto, V.G., Mourad-Zeidan, A.A., Melnikova, V., Johnson, M.M., Lopez, A., Diwan, A.H., Lazar, A.J., Shen, S.S., Zhang, P.S., Reed, J.A., et al., 2006. Galectin-3 expression is associated with tumor progression and pattern of sun exposure in melanoma. Clinical Cancer Research 12, 6709-6715.

[48] Puig-Butille, J.A., Vinyals, A., Ferreres, J.R., Aguilera, P., Cabré, E., Tell-Martí, G., Marcoval, J., Mateo, F., Palomero, L., Badenas, C., et al., 2017. Aurka overexpression is driven by foxm1 and mapk/erk activation in melanoma cells harboring braf or nras mutations: impact on melanoma prognosis and therapy. Journal of Investigative Dermatology 137, 1297-1310.

[49] Rahman, M.R., Islam, T., Zaman, T., Shahjaman, M., Karim, M.R., Huq, F., Quinn, J.M., Holsinger, R.D., Gov, E., Moni, M.A., 2020. Identification of molecular signatures and pathways to identify novel therapeutic targets in alzheimer's disease: Insights from a systems biomedicine perspective. Genomics 112, 1290-1299.

[50] Richards, M.W., O’Regan, L., Mas-Droux, C., Blot, J.M., Cheung, J., Hoelder, S., Fry, A.M., Bayliss, R., 2009. An autoinhibitory tyrosine motif in the cell-cycle-regulated nek7 kinase is released through binding of nek9. Molecular cell 36, 560-570.

[51] Rollakanti, K., Anand, S., Maytin, E.V., 2015. Topical calcitriol prior to photodynamic therapy enhances treatment efficacy in non-melanoma skin cancer mouse models, in: Optical Methods for Tumor Treatment and Detection: Mechanisms and Techniques in Photodynamic Therapy XXIV, International Society for Optics and Photonics. p. 93080Q.

[52] Rosette, C., Karin, M., 1996. Ultraviolet light and osmotic stress: activation of the jnk cascade through multiple growth factor and cytokine receptors. Science 274, 1194-1197.

[53] Rünger, T.M., Vergilis, I., Sarkar, P., DePinho, R.A., Sharpless, N.E., 2005. How disruption of cell cycle regulators might predispose to sun-induced skin cancer. Cell Cycle 4, 643-645.

[54] Sandelin, A., Alkema, W., Engström, P., Wasserman, W.W., Lenhard, B., 2004. Jaspar: an openaccess database for eukaryotic transcription factor binding profiles. Nucleic acids research 32, D91D94.

[55] Schmit, T., Zhong, W., Nihal, M., Ahmad, N., 2009. Polo-like kinase 1 (plk1) in non-melanoma skin cancers. Cell Cycle 8, 2697-2702.

[56] Schöffski, P., 2009. Polo-like kinase (plk) inhibitors in preclinical and early clinical development in oncology. The oncologist 14, 559-570.

[57] Shannon, P., Markiel, A., Ozier, O., Baliga, N.S., Wang, J.T., Ramage, D., Amin, N., Schwikowski, B., Ideker, T., 2003. Cytoscape: a software environment for integrated models of biomolecular interaction networks. Genome research 13, 2498-2504.

[58] Sheppard, K.E., McArthur, G.A., 2013. The cell-cycle regulator cdk4: an emerging therapeutic target in melanoma. Clinical Cancer Research 19, 5320-5328.

[59] Shi, X., Li, H., Shi, A., Yao, H., Ke, K., Dong, C., Zhu, Y., Qin, Y., Ding, Y., He, Y.H., et al., 2018. Discovery of rafoxanide as a dual cdk $4 / 6$ inhibitor for the treatment of skin cancer. Oncology reports $40,1592-1600$.

[60] Szklarczyk, D., Franceschini, A., Kuhn, M., Simonovic, M., Roth, A., Minguez, P., Doerks, T., Stark, M., Muller, J., Bork, P., et al., 2010. The string database in 2011: functional interaction networks of proteins, globally integrated and scored. Nucleic acids research 39, D561-D568.

[61] Takada, K., Amano, S., Kohno, Y., Nishiyama, T., Inomata, S., 2006. Non-invasive study of gelatinases in sun-exposed and unexposed healthy human skin based on measurements in stratum corneum. Archives of dermatological research 298, 237-242.

[62] Tang, Z., Li, C., Kang, B., Gao, G., Li, C., Zhang, Z., 2017. Gepia: a web server for cancer and normal gene expression profiling and interactive analyses. Nucleic acids research 45, W98-W102.

[63] Tetsu, O., McCormick, F., 2003. Proliferation of cancer cells despite cdk2 inhibition. Cancer cell 3 , 233-245. 
[64] Torre, D., Lachmann, A., Ma'ayan, A., 2018. Biojupies: automated generation of interactive notebooks for rna-seq data analysis in the cloud. Cell systems 7, 556-561.

[65] Van Der Pols, J.C., Xu, C., Boyle, G.M., Parsons, P.G., Whiteman, D.C., Green, A.C., 2006. Expression of p53 tumor suppressor protein in sun-exposed skin and associations with sunscreen use and time spent outdoors: a community-based study. American journal of epidemiology 163, 982-988.

[66] Vízkeleti, L., Ecsedi, S., Rákosy, Z., Orosz, A., Lázár, V., Emri, G., Koroknai, V., Kiss, T., Ádány, R., Balázs, M., 2012. The role of ccnd1 alterations during the progression of cutaneous malignant melanoma. Tumor Biology 33, 2189-2199.

[67] Ward, W.H., Farma, J.M., 2017. Cutaneous melanoma: etiology and therapy [internet] .

[68] Wu, X., Yan, J., Yu, J., Yu, J., Cheng, Z., Yin, T., Guo, Q., Xie, Y., Kong, Y., Guo, J., 2020. Frequency of cdk2, ccne1 copy number variation in acral melanoma and implications for cdk inhibitor in targeted therapy .

[69] Xia, J., Gill, E.E., Hancock, R.E., 2015. Networkanalyst for statistical, visual and network-based meta-analysis of gene expression data. Nature protocols 10, 823-844.

[70] Yang, G., Zhang, G., Pittelkow, M.R., Ramoni, M., Tsao, H., 2006. Expression profiling of uvb response in melanocytes identifies a set of p53-target genes. Journal of investigative dermatology $126,2490-2506$.

[71] Yu, J., Yan, J., Guo, Q., Chi, Z., Tang, B., Zheng, B., Yu, J., Yin, T., Cheng, Z., Wu, X., et al., 2019. Genetic aberrations in the cdk4 pathway are associated with innate resistance to pd-1 blockade in chinese patients with non-cutaneous melanoma. Clinical Cancer Research 25, 6511-6523.

[72] Zhang, N., Pati, D., 2017. Biology and insights into the role of cohesin protease separase in human malignancies. Biological Reviews 92, 2070-2083. 